\title{
Awareness and Attitude of Family Planning among Rural Women of Nsukka Local Government Area: Implications for Social Work Intervention
}

\author{
Ngwu Christopher Ndubisi (Ph.D)
}

\author{
Department of Social Work, Faculty of the Social Sciences, University of Nigeria, Nsukka \\ Email: ngwuchris@yahoo.com
}

\section{Doi:10.5901/mjss.2014.v5n27p1404}

\begin{abstract}
Nigeria's population increase has become a great concern to demographers, economic planners and even the government agents as a result of people's apathy in family planning. Many of the rural population are not knowledgeable about the benefits of family planning and as such, they feel that the programs are not for them, and therefore, do not participate. Against this backdrop of the above situation, the study examined the awareness and attitude of family planning among rural women of Nsukka Local Government Area. Data were gathered from 240 respondents who were randomly selected from Nsukka rural communities. Results showed that younger women (55.2\%) were more knowledgeable about family planning than the older women (44.8\%). It was also found that religion played an active role in the adoption of family planning practices in Nsukka area of Enugu State. In view of this, it is strongly recommended that education should be employed to improve people's knowledge on sexuality and to curtail the ugly trends in family planning practices in Nigeria.
\end{abstract}

Keywords: Awareness, Attitude, Family Planning, Social Work, Rural, Nsukka.

\section{Introduction}

Family planning has attracted attentions all over the world due to its relevance in decision making, population growth and development. Samuel (2010) defined family planning as the practice that helps individuals or couples to attain certain objectives such as avoiding unwanted pregnancies, bringing about wanted babies at the right time, regulating, the interval between pregnancies, controlling the time at which birth occurs in relation to the ages of parents and determining the number of children in the family. Family planning is a means of reproductive health. In-spite of the hue and cry in and outside Nigeria about family planning or birth control, many people are still confused about its meaning, the methods involved, the advantages and disadvantages and the factors hindering it's wide application in Nigeria (Iffih and Ezeah, 2004).

According to free Encyclopedia (2013) family planning is of birth control and other techniques to implement such plans which include sexuality education, prevention and management of sexually transmitted infections, pre-conception counseling and management of infertility. It further conceptualizes that family planning is educational, comprehensive medical or social activities which enable individuals to determine freely the number and spacing of their children and to select the means by which this may be achieved.

Brown et al (1987) argued that majority of the traditional societies welcome family planning practices because they are linked to the world communication and transportation networks which carry ideas and messages on contraceptive use. On the other hand, some societies do not accept family planning due to their cultural practices. Take for instance, Nigerian culture take delight in son preference. A typical example of son preference in Igbo societies is shown when married couples with female children shun family planning so that they will be able to raise male children who are accorded more importance than females because males propagate family name, property and inheritance laws which limit the rights of females and can reinforce son preference. Research has shown that culture is a determinant for acceptance and non-acceptance of family planning.

Women's education resulted in woman empowerment and it enables them to use family planning services more effectively. WHO (1993) found out that women's education is in line with lower fertility which constitutes management of reproductive resources. Maternal education has once been linked with reduction of child mortality among rural dwellers. Women's education enhances their capability and also their reproductive rights to decide freely and responsibly the number, spacing and timing of their children and to have other necessary information regarding reproductive rights. Studies have shown that education is a determinant of awareness of family planning practices in Nigeria, for instance; Olaitan (2011) conducted a study on factors influencing the choice of family planning among couples in South West, 
Nigeria. The findings revealed that educational background of the couples significantly influenced the choice of family planning among couples.

Recent studies have also shown that religion is a good determinant of family planning practices. United Nation (1997) identified some factors such as cultural background, and religions beliefs which place the women at disadvantaged position in reproductive health issues. Ezea and Iffih (2004) asserted that Catholic Church is rigid in their views of family planning. Catholics hold the view that the application of artificial method is wrong and should not be allowed. The Catholic Church is said to be comfortable with the use of Billings's ovulation method which is rather natural. Igbudu et al (2011) conducted a study on the relationship between religious beliefs and family planning practices of married women in zone 5 barracks of the Nigeria police, comprising Edo, Delta, and Bayesa state commands. The findings of the study revealed that attitudinal factor such as the strong religious desire for more children prevented women in these barracks from using family planning.

It has been noted that women of high socio-economic status are likely to engage in family planning practices than women of low socio-economic status in Nigeria. Most of the women with high socio-economic status are linked to the knowledge/awareness and acceptance of family planning practices because they can foot the bills associated with family planning. Family planning has a great potential for reducing mortality in Nigeria. The main thrust of this work is to ascertain the attitude and the extent of awareness of married mothers toward family planning and also to examine whether educational background, gender, Age, Religion, culture and socio-economic background of mothers are determinants of family planning practices in Nsukka LGA.

\section{Theoretical Framework}

Social cognitive theory which has been recognized widely for providing a framework for understanding human behaviour was adopted to anchor this study. Social cognitive theory centers on the prominent role of social modeling in human motivation, learning, thought and action. In social cognitive theory, the "social" aspect of the title acknowledges the social origins of human thought and action while the "cognitive " aspect recognizes the influential contribution of cognitive processes to human motivation, affect, and action (Bell, 2007). Social cognitive theory is rooted in the perspective that people are self-organizing, pro-active and self-regulating. Human behaviour is the product of an active interplay of personal, behavioural and environmental influences (Pajares, 2004)

Social cognitive theory assumes that if one is motivated to learn a particular behaviour, then that particular behaviour would be learned through clear observations. By imitating these observed actions, the individual observer would solidify that learned action. Social cognitive theory is a learning theory based on the ideas that people learn by watching what others do and that human thought process are central to understanding personality.

Bell (2007) argues that social cognitive theory is concerned with how humans operate cognitively on their experiences and how these cognitive operations then come to influence their behavour. People are believed to abstract and integrate information that is encountered in a variety of experiences. From this abstraction and integration, people can represent their environments and themselves in terms of certain crucial classes of cognitions, including, but not limited to attitudes and values. These cognitions are believed to affect the behaviours of individuals (Bandura, 1986).

This study will investigate areas that may hinder women from the knowledge of accessing the available information on family planning services. It has been noted that access and availability of information enhances rightful choices of family planning. When people are well informed on an issue, they act appropriately. Adequate information on family planning services is beneficial to all and sundry including men, women, children, families, governments and the world at large. The knowledge of family planning services will help to protect women from unwanted pregnancies thereby saving them from high risk pregnancies or unsafe abortions. Thus, social cognitive theory can be useful in developing a training program to address the provision of family planning information by social workers, once it is known what needs to be confronted (Bell, 2007).

\section{Material and Methods}

The study was located in Nsukka Local Government Area (LGA) of Enugu State, Nigeria and was undertaken among rural women of reproductive ages (18-49 years). A cross sectional design was used to measure the awareness and attitude of family planning among rural women in Nsukka Local Government Area. The chi-square test was used in order to test for the association of variables. The sample for this study consisted of 240 respondents (females only) selected through simple random sampling methods from the three communities (Anuka, Lejja and Okpuje) of Nsukka Local Government Area, though the study made use of 230 respondents of those who returned their questionnaires. 
A structured questionnaire on the awareness and attitude of family planning was used for the data collection. The first part of the questionnaires was designed for women of reproductive ages (18 - 49 years). The data collected was processed and analyzed using statistical packages for social sciences (SPSS). A descriptive of statistical packages for social sciences was used. The first part of analysis started with socio- demographic characteristics of respondents such as marital status, sex, Age, education and occupation. The second part of this analysis used frequency, simple percentages and chi-square to test the variables.

\section{Data and Descriptive Statistics}

Socio-demographic characteristics collected in the questionnaire included age of the respondents, marital status, religion, occupation and educational attainment of the respondents. The study showed that majority of the respondents (96.1\%) were married and only (3.1\%) and (.9\%) were divorced/separated and single respectively. Distribution of respondents by age showed that $27 \%$ of the respondents were within the age of $20-29$ years while $50.5 \%$ fall within the age of $30-39$ years.

The findings of the educational qualification of the respondents showed that most of them (30.9\%) were holders of senior school certificate of education (SSCE) while $27 \%$ of them fall within the range of those who posses' first school leaving certificate (FSLC). $9.1 \%$ of the respondents had no formal education and $17 \%$ and $16 \%$ had their Ordinary National Diploma (OND) and Degree Certificate respectively. Most of the respondents (37\%) from the petty trading groups dominated the sample population and notable among the other groups in the sample were the farmers (27.4\%) and civil servants (26.1\%). The study also showed that (90.4\%) of the respondents were Christians while African Traditional Religion and Muslims represented $4.8 \%$ and $2.2 \%$ respectively.

Table 1: Percentage Distribution of Respondents by background Information

\begin{tabular}{|c|c|c|c|}
\hline Age range & Frequency & Percent & Valid percent \\
\hline $20-29$ & 62 & 27.0 & 27.0 \\
\hline $30-39$ & 116 & 50.5 & 50.5 \\
\hline 40 and above & 52 & 22.5 & 22.5 \\
\hline Total & 230 & 100.0 & 100.0 \\
\hline \multicolumn{4}{|c|}{ MARITAL STATUS: } \\
\hline Single & 2 & .9 & .9 \\
\hline Married & 221 & 96.1 & 96.1 \\
\hline Separated & 2 & .9 & .9 \\
\hline Divorced & 5 & 2.2 & 2.2 \\
\hline Total & 230 & 100.0 & 100.0 \\
\hline \multicolumn{4}{|c|}{ EDUCATIONAL QUALIFICATION } \\
\hline No Formal Education & 21 & 9.1 & 9.1 \\
\hline First School Leaving Certificate & 62 & 27.0 & 27.0 \\
\hline Senior School Certificate & 71 & 30.9 & 30.9 \\
\hline National Diploma & 39 & 17.0 & 17.0 \\
\hline Degree & 37 & 16.0 & 16.0 \\
\hline Total & 230 & 100.0 & 100.0 \\
\hline \multicolumn{4}{|c|}{ OCCUPATION } \\
\hline Artisan & 22 & 9.6 & 9.6 \\
\hline Farmer & 63 & 27.4 & 27.4 \\
\hline Civil servant & 60 & 26.0 & 26.0 \\
\hline Petty trader & 85 & 37.0 & 37.0 \\
\hline Total & 230 & 100.0 & 100.0 \\
\hline \multicolumn{4}{|c|}{ RELIGIOUS AFFILIATION } \\
\hline Christianity & 208 & 90.4 & 90.4 \\
\hline Islam & 5 & 2.2 & 2.2 \\
\hline African traditional religion & 11 & 4.8 & 4.8 \\
\hline Others & 6 & 2.6 & 2.6 \\
\hline Total & 230 & 100.0 & 100.0 \\
\hline
\end{tabular}

Source: Ngwu, C.N (2013) 
The table 2 below showed the differences between the level of education and awareness of family planning methods in Nsukka rural communities. The findings revealed that respondents with high level of education are more aware of family planning than those with lower level of education. Table 2 also examined the age related differences in awareness of family planning among rural women of Nsukka local government area (LGA). The study also explored the relationship between religion and acceptance of family planning method among the rural populace in Nsukka LGA.

Table 2: Distribution of Respondents According To Awareness of Family Planning, Relationship between Religion and Family Planning and Knowledge Difference between Older and Younger Women on Family Planning

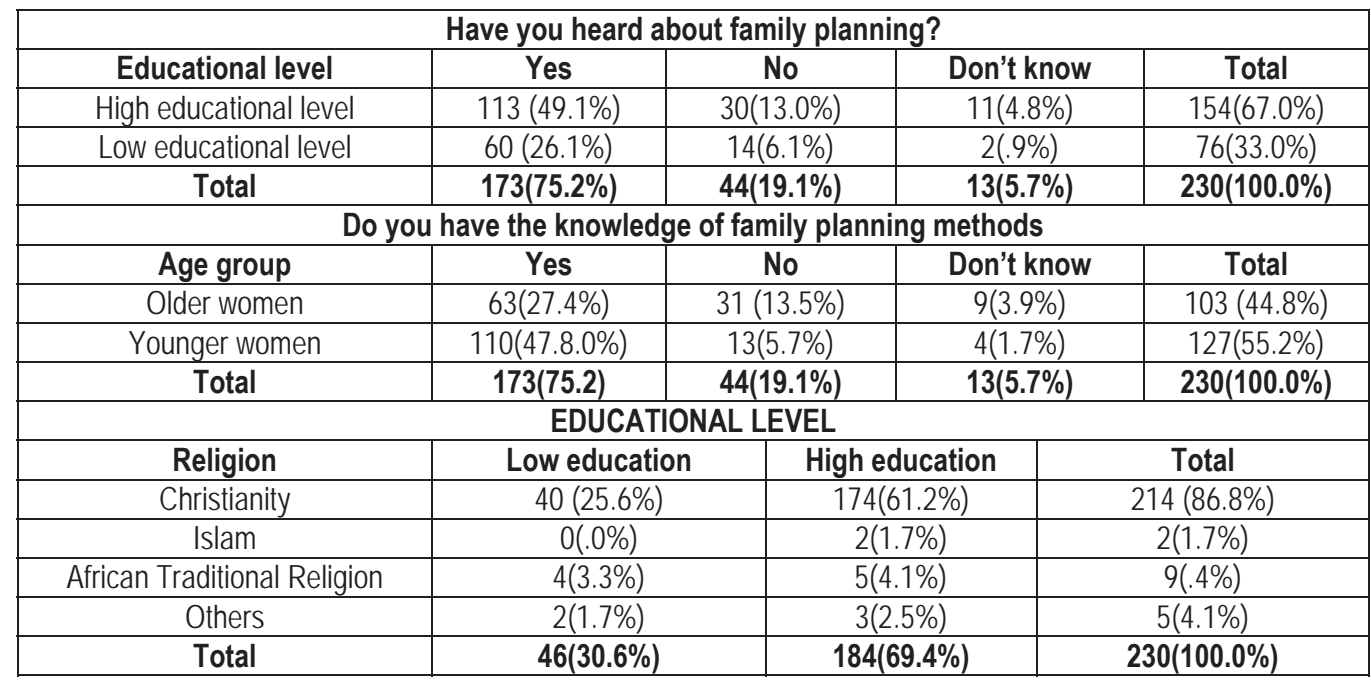

Source: Ngwu C.N. (2013)

\subsection{Awareness and Attitude Measures}

Results from the study showed that younger respondents (55.2\%) were more knowledgeable about family planning than the older respondents (44.4\%). The study also revealed the differences between the level of education and awareness of family planning methods in Nsukka LGA. The findings showed that women with high level of education have more knowledge of family planning that those with lower level of education. The results also revealed the unwillingness or apathy of the rural women on the practice of family planning in Nsuka LGA. This was as a result of religious factors or cultural practices of the people. Many of the respondents (40.4\%) believed that children come from God and therefore there is no need planning or controlling fertility.

When the respondents were asked the reasons for lack of adoption of family planning, $56 \%$ of them opted for religious beliefs while $44 \%$ supported lack of knowledge. This shows that religion is a good determinant of family planning in Nigeria. Some women, who may have died as a result of refusal to use contraceptives, could have died as a result of religious belief. Religion is said to have played an active role in the adoption of family planning practices in Nsukka LGA of Enugu State. In Nigeria, religion has been identified as one of the determinant factors that affect family planning practices.

Furthermore, the study revealed that women have knowledge of family planning than men. Studies have shown that there are educated women that have knowledge of family planning, but are not practicing it due to the influence of their husbands; this is referred to as unmet need of the family planning. When the respondents were asked whether they have at any point in time practiced any family planning methods, $53 \%$ of them agreed to have practiced family planning while a large proportion (47\%) denied having ever practiced family planning. This attitude of failing to practice family planning could be linked to the cultural or religious beliefs of the people of Nsukka area. For those who practice family planning, only $31 \%$ adopted the natural method of planning while a greater percentage (69\%) are said to be practicing artificial method.

Finally, the study showed that cultural sensitivities account for the knowledge and use of family planning in Nsukka LGA of Enugu State, Nigeria. The position of ideas, meaning, beliefs and values, people learn as members of society determine human nature. People are what they learn and practice (Neil, 2006). 


\section{Discussion}

The major thrust of this research was to examine the awareness and attitude of family planning among rural women of Nsukka LGA. In the study, it was revealed that women with high level of education are more knowledgeable about family planning methods than those with lower level of education. Educated women are much more likely to know more than one method of family planning than the uneducated women. Numerous studies indicate that women's educational status and decision making are positively associated with the use of family planning (Bandura, 2002). Beekle (2006) argued that educated women are often incorporated into family planning programmes and counseling through different communication channels including the mass media. Formal education for both men and women may result in increased acceptance of the family planning in the society. UNICEF (2005) study revealed that in Nigeria, $96 \%$ of women with secondary and high education and $47 \%$ of those with no formal education had sought family planning services in the past two years. In Nigeria, many families or marriages have suffered irreparable loss as a result of lack of knowledge on the issues of health care services (Ngwu et al 2013).

The high percentage response on the reasons for lack of adoption of family planning in this study means that religion has traditionally been seen as a barrier to fertility decline and the adoption of family planning in Nigeria. Olaitan (2011) posits that catholic church have restrictions on contraception based on the belief that it is God's will to bring children into the world. This restriction can lead to frequent child bearing which can result to maternal deaths. Hence, religion influences people's reasoning and behavioural attitude in their disposition to issues especially in sexual relationship (Coleman, 2002). This was in line with the study carried out by Igbudu et al (2011) which observed that attitudinal factor such as the strong religious desire for more children prevented women from using family planning. In Nigeria, as we have noted earlier, that religion has been identified as one of the determinant factors that affects family planning.

The study also showed that women are more knowledgeable about family planning than men. The study noted that $59 \%$ of the respondents agreed that women have knowledge of family planning than men while only $16 \%$ of them did not support the idea of women having more knowledge. Women ranked highest in the awareness of family planning and have demonstrated superior knowledge over their male counterparts. The results, however showed that there is a significant difference between sex of respondents and the awareness of family planning $x^{2}(2, N=230)=69.452, p \leq 0.000$. In this regard, women require more social support to enable them fulfill their productive and reproductive role. The ability of women to apply knowledge of contraceptives depends on this basic understanding of family planning. WHO (2014) holds the view that gender is the socially constructed roles and the relationship between men and women. Generally, women are more engaged in family planning methods than men because women carry the burden of child bearing and nurture more than men. Despite the difficulties that couples experience, those who can plan their families are more likely to have a much better chance of overcoming problems and staying together than those who do not plan their families. In Nigeria many marriages have failed because of lack of knowledge on family planning.

Finally, the study noted that majority of the respondents (53\%) had practiced family planning whereas only (47\%) had failed to practice family planning at all. Therefore, it does appear that many of the respondents have learnt that family planning has a lot of advantages which entails deciding freely and responsibly the number, spacing and timing of their children. Nevertheless, the $47 \%$ of the sample population who had not practiced family planning cannot be swept under the carpet because they are simply large enough. The reason for this kind of result may be clear because cultural sensitivities account for the knowledge and use of family planning in most of the developing countries of the world. One can conclude that cultural belief is linked to the negative attitude towards acceptance of family planning. In this case, there is probably no aspect of expression that does not have its cultural determinants and because the patterns of attitude and behaviours set by different cultures may vary greatly, they frequently constitute significant barriers to family planning.

\section{Implications for Social Work Intervention}

The profession of social work has a long history of supporting access to birth control (Bell, 2007). The support for family planning continues today within the field of social work. In order to authenticate the stand of social work on family planning, issues, the National Association of social workers (NASW) issued a policy statement on family planning which was approved in 1975 and upheld in 1991. The policy states that "a woman's right of choice in family planning is consistent with the principles of self- determination, empowerment and dignity that form the foundation of social work. However, social workers are known to have been at the frontline of policy and direct care of the most affected by access of family planning. 
Social workers are expected to bring about positive changes through the means of counseling both men and women on the apathy or unwillingness to practice family planning. For instance, the study showed that $40 \%$ of the respondents believed that children come from God and therefore, could not subscribe to family planning. This is dangerous because these beliefs and practices have adverse effects on the family planning in Nigeria. Social workers should raise awareness and increase understanding of issues affecting family planning amongst policy makers and general population through advocacy and social mobilization. Social worker's effective advocacy will certainly help to reduce people's cultural inclinations for instance, in the study, it was indicated that $56 \%$ of the respondents opted for religious beliefs as the reasons for lack of adoption of family planning in Nsukka local government area of Enugu State, Nigeria.

This can also attest that Religion is problem not only due to its effect on women's societal position but also because of harmful beliefs and traditions relating to childbirth. Social workers assist men and women by helping them cope with issues in their everyday lives, deal with their relationships and solve personal and family problems. Social workers conduct services and are involved in family planning. They research and analyze policies, programs and regulations concerning family planning. Social workers are not expected to be family planning medical experts; rather they provide individuals with needs assessment and information about family planning services. The social worker's attentions are focused on the family planning program objectives such as:-

$>$ Reducing unintended pregnancies

$>$ Educating both men and women on the available family planning services

$>$ Providing both men and women with information and link them to the available family planning services. Social workers are expected to provide information to people on the available services, where to access services or a referral to the social service case worker upon request.

Access and availability of information enhances rightful choices of family planning (contraceptive choice). To this end, social workers should engage in communication campaigns to help people have access to information so that they will make right choices. According to Agema and Adi (2006), the manner by which knowledge about family planning is communicated will determine how widely that knowledge will be acted upon. It is therefore, important for social workers to identify appropriate means of information dissemination and health wise choices, people need to know about family planning, have access to a range of methods and have access to information

\section{Conclusion}

The findings from the present study suggest that religious beliefs and cultural sensitivities are contributory factors to Nigeria's population increase which have become a great concern to economic planners and demographers. The research also noted that the major constraints to family planning in Nsukka LGA include; cultural practices, religion and ignorance. However, there is need for social workers to work toward changing these ugly trends associated with population explosion and cultural practices of people which have continued to contribute to maternal mortality in Nigeria. Social workers should employ education and counseling to curtail the apathy or unwillingness of the rural women on the practice of family planning in Nigeria. Formal education is hereby recommended for both men and women who may result in increased acceptance of the family planning in the society.

\section{References}

Bandura A (2002). Environmental Sustainability by Socio Cognitive Deceleration of Population Growth. In the Psychology of Sustainable Development. Pp. 209 - 238.

Bandura, A (1986). Social foundations of thought and action: A social cognitive theory. Englewood Cliifs, N.J: Prentice Hall

Beekle A \& Mccabe, C (2006). Awareness and determinants of family planning practice in Jimna, Ethiopia. Journal of international council of Nurses $53,269-276$

Bell, M (2007). "Barriers in the provision of family planning information from social workers to their clients", Ph.D thesis submitted to the graduate faculty of the school of social work, University of Pittsburgh

Brown J; Coetaux F, Chipoma R, Manda V, \& Muntemba D (1987). Characteristics of contraceptive Acceptors in Lusaka, Zambia. Studies in family planning: population council: 18 (2) 96-102.

Coleman, E (2002). Masturbation as a means of achieving sexual health: Journal of psychology and Human sexuality, 14 (213) 5-14

Free Encyclopedia (2013). Definition of Family Planning: http://wikipedia.org/wiki/family planning. Date accessed 25/01/13

Iffih, B \& Ezeah, P (2004). Sociology of Family; Enugu, John Jacob classic publishers limited

Igbudu U, Okoedions S, Peremene E \& Eghafona K (2011). Religious beliefs and family practices of married women in zone 5, police barracks in Nigeria, Ozea journal of social sciences. 
Morunkola O, Ojediran, M \& Amosu, A (2006). Reproductive health knowledge, beliefs and determinants of contraceptive use among attending family planning clinics in Ibandan, Nigeria. African journal of health science 13 (3) 37-52

Neil O. (2006). Human culture. What is culture? http://thropaloma..........

Ngwu, C \& Onah, N (2013) Socio-cultural factors influencing maternal mortality in Enugu state, South Eastern Nigeria. Asian Academic Research Journal of Social Science and Humanities. www.asianacademicresearch.org vol.1 issue 18. pp. 36-51

Olaitan, O (2011). Factors Influencing the choice of family planning among couples in south west, Nigeria. International journal of medicine and medical sciences. http//:www.academic-journal.org/ijmms. 3 (7) - 232 retrieved 20/3/2013

Samuel, E (2010). Human Sexuality \& Family Health Education, Nsukka, Afro-Orbis publication Limited UNICEF (2005). Analysis of the situation of children and women in Nigeria Lagos and New York, UNICEF.

WHO (1993). "The health of the family" No 6 Nov, - Dec. 1993.

WHO (2014). Family planning www.who.int/topics/family-planning/en/. Date retrieved 26/2/2014

WHO (2014). Gender Mainstreaming; http:// www. Who.int/gender/gender mainstreaming/e.......... Date retrieved 26/2/2014. 